\title{
PENGEMBANGAN BIG BOOK SEKOLAH DASAR
}

\author{
Mahmud Alpusari ${ }^{1,2^{*}}$, Eva Astuti Mulyani ${ }^{1}$, Riki Apriyandi Putra ${ }^{4}$, Neni Hermita ${ }^{1,3}$ \\ ${ }^{1}$ Prodi PGSD FKIP Universitas Riau \\ ${ }^{2}$ Prodi PPG FKIP Universitas Riau \\ ${ }^{3}$ Prodi Pendidikan IPA FKIP Universitas Riau \\ ${ }^{4}$ Prodi Pendidikan Biologi FKIP Universitas Riau \\ *mahmud.alpusari@lecturer.unri.ac.id
}

Accepted: March $15^{\text {th }}, 2020$

\begin{abstract}
This study aims to assist teachers in developing learning media in elementary schools, namely the big book. This study uses a developmental research type with the Thiagarajan 4-D Model which consists of 4 stages, namely, define, design, develop, and disseminate. The research was conducted at PGSD of FKIP, Universitas Riau. The object of this research is the big book of elementary school students developed from the basic competencies in the 2013 curriculum. The products produced are 3 big books with the title Sekolahku, Wisata ke Pantai and Taman Kota. The results of the validation of the three big book titles carried out by experts, the feasibility of the content of the material obtained by the percentage of scores for the title Sekolahku 82.1\%; Wisata ke Pantai 82.1\%; and Taman Kota $86 \%$. Meanwhile, for the big book language assessment, the percentage for Sekolahku was 79.9\%; Wisata ke Pantai 79.7\%; and Taman Kota 82.5\%. So that the big book learning media is feasible to be tested with revisions according to suggestions.
\end{abstract}

Keywords: big book; elementary school; learning media

\section{PENDAHULUAN}

Pembelajaran membaca di SD dilaksanakan di kelas rendah yang dikenal dengan pelajaran membaca permulaan. Tujuan membaca permulaan di kelas satu adalah agar siswa dapat membaca kata-kata dan kalimat sederhana dengan lancar dan tepat, Depdikbud (Rusminiati, dkk, 2018). Kelancaran dan ketepatan anak membaca pada tahap belajar membaca permulaan dipengaruhi oleh keaktifan dan kreativitas guru yang mengajar. Kemampuan membaca permulaan tersebut yakni dengan kegiatan membaca bersama, kegiatan ini bertujuan untuk melatih siswa menyuarakan lambang-lambang tertulis. Melalui kegiatan ini siswa 
dibiasakan membaca dengan intonasi yang wajar, tekanan yang baik, dan lafal yang benar.

Siswa yang kesulitan membaca sering memperlihatkan kebiasaan dan tingkah laku yang tidak wajar. Gejala-gejala gerakannya penuh ketegangan seperti gelisah, irama suara meninggi, dan menggigit bibir. Di samping itu, siswa merasa kesulitan dalam hal siswa tidak mengenali huruf, siswa sulit membedakan huruf dan siswa kurang yakin dengan huruf yang dibacanya itu benar. Selain itu, saat guru mengajarkan membaca masih ada siswa yang terlihat kurang antusias, malas, dan kurang aktif. Selain itu, guru juga hanya menggunakan buku ajar dari sekolah dalam mengajarkan membaca kepada siswa. Dengan kenyataan tersebut, akhirnya siswa merasa cepat bosan dalam menerima pelajaran, dan siswa tidak termotivasi untuk mengenal dan memahami materi yang disajikan. Terdapat banyak metode yang dapat digunakan untuk mengajarkan membaca kepada siswa di kelas rendah. Metode tersebut seperti metode abjad, metode eja, metode kata, metode global, metode SAS, metode membaca bersama, metode suku kata, metode membaca terbimbing.

Berdasarkan sekian banyak metode dalam membaca, maka metode membaca bersama dianggap sangat tepat digunakan. Membaca bersama perlu adanya media dalam pembelajaran. Media memiliki peran penting dalam meningkatkan ketertarikan siswa untuk belajar membaca. Salah satu media yang digunakan dalam membaca bersama adalah big book.

Buku Besar (Big Book) adalah buku bacaan yang memiliki ukuran, tulisan, dan gambar yang besar. Ukuran big book harus mempertimbangkan segi keterbacaan seluruh siswa di kelas. Big Book dapat digunakan di kelas awal karena memiliki karakteristik yang sesuai dengan kebutuhan siswa. Guru dapat memilih Big Book yang isi cerita dan topiknya sesuai dengan minat siswa atau sesuai dengan tema pelajaran. Bahkan, guru dapat membuat sendiri Big Book sesuai dengan kebutuhan. Dengan demikian peneliti melihat perlu pengembangan media Big Book sebagai sarana media pembelajaran membaca bersama. Melalui Big Book, siswa diharapkan dapat memberikan kesempatan kepada siswa untuk terlibat dalam kegiatan membaca dengan cara yang menarik. 


\section{METODE PENELITIAN}

Penelitian ini dilaksanakan di Kampus FKIP PGSD Universitas Riau. Untuk uji coba terbatas dilaksanakan di SDN 192 dan SDN 194 Pekanbaru. Waktu penelitian 9 bulan terhitung dari bulan Maret sampai dengan November 2020. Objek penelitian ini merupakan big book siswa sekolah dasar yang dikembangkan dari kompetensi dasar pada Kurikulum 2013. Pada penelitian ini digunakan jenis penelitian pengembangan atau biasa dikenal dengan developmental research. Penelitian pengembangan dapat diartikan sebagai rangkaian proses atau langkahlangkah untuk mengembangkan suatu produk yang efektif dan berupa bahanbahan pembelajaran, media, strategi pembelajaran untuk digunakan di sekolah, dan bukan menguji teori (Dharma dalam Putra, 2015; Febriyanti, \&Putra, 2020; Putri, Putra, \& Munjiatun, 2021; Satria \& Hajani, 2020; Suhandi \& Pamela, 2019;). Pada penelitian ini peneliti mengembangkan big book siswa Sekolah Dasar. Model pengembangan yang digunakan mengacu pada model 4-D yang terdiri dari 4 tahap yaitu, pendefinisian (define), perancangan (design), pengembangan (develop), dan penyebaran (disseminate), Thiagarajan (Mulyatiningsih, 2011).

Teknik pengumpulan data yang digunakan dalam penelitian ini angket yang divalidasi dan respon guru. Angket validasi diberikan kepada validator yaitu ahli media pembelajaran, ahli materi membaca, ahli bahasa, dan guru kelas I dan II sebelum dilakukan uji coba di lapangan. Tujuannya adalah untuk mendapatkan penilaian dan masukan tentang big book yang dikembangkan sehingga bahan ajar tersebut valid dan layak untuk diujicobakan secara terbatas.

\section{HASIL DAN PEMBAHASAN}

Penelitian ini dilakukan mengikuti tahap-tahap pengembangan model 4-D menurut Thiagarajan yang terdiri dari 4 tahap yaitu, pendefinisian (define), perancangan (design), pengembangan (develop), dan penyebaran (disseminate).. Hasil penelitian dideskripsikan sebagai berikut.

Pada tahap pendefinisian (define) dilakukan pengkajian kurikulum 2013 yang digunakan di sekolah dasar. Disini peneliti melakukan analisis tema dan sub tema pada kelas II. Peneliti mengambil tema 2 sebagai tema untuk pengembangan big book, selanjutnya menetapkan kompetensi dasar dan indikator pencapaian 
TUNJUK AJAR: JURNAL PENELITIAN ILMU PENDIDIKAN

Volume 4, Nomor 1, February 2021

P-ISSN: 2615-062X

E-ISSN: 2622-3554

http://dx.doi.org/10.31258/ita.v4i1.86-95

pembelajaran sebagai acuan dalam pengembangan bigbook. Peneliti melanjutkan menganalisis karakteristik peserta didik, untuk mempertimbangkan kemampuan akademik siswa kelas II dalam menyusun materi bigbook agar sesuai dengan dengan kemampuan tingkat berpikir siswa kelas II. Dalam menganalisis materi peneliti melakukan identifikasi terhadap tema dan sub tema pada kurikulum 2013. Analisis terhadap kurikulum yang dilakukan peneliti bertujuan untuk menyesuaikan isi materi dalam media Big Book terhadap kurikulum yang ada di sekolah dasar.

Tahap perancangan (design) dilakukan pemilihan media yang sesuai dengan karakteristik siswa kelas II. Bigbook didesain sedemikian rupa agar terlihat menarik perhatian siswa. Pada proses perancangan big book ini, peneliti juga melakukan perancangan instrumen untuk melakukan penilaian dengan penyusunan instrumen penilaian serta angket untuk menilai produk yang berisi checklist untuk ahli materi, ahli media, dan ahli perangkat

Tahap pengembangan (develop), Pembuatan media big book menggunakan aplikasi gambar bernama Corel Draw X7. Big book ini dikembangkan sesuai materi serta gambaran yang telah dirancang oleh pengembang sejak awal. Produk yang merupakan desain awal big book disebut draft I. Ada 3 big book yang dirancang dengan judul Sekolahku, Wisata Pantai dan Taman Kota. Adapun hasil pengembangan big book dapat dilihat pada gambar 1 .

Selanjutnya dilakukan validasi ahli media Big Book setelah usai di desain, langkah berikutnya yaitu pemvalidasian hasil produksi kepada para ahli. Terdapat dua jenis validasi, yaitu validasi materi dan media. Kegiatan validasi dilaksanakan dengan ahli materi dan ahli media. Hasil yang diperoleh dari validasi akan diambil sebagai acuan untuk kegiatan revisi tahap I untuk pengembangan produk. Hasil validasi oleh validator menunjukkan data yang diperoleh sudah sangat baik. Data tersebut dapat dijabarkan sebagai berikut. 


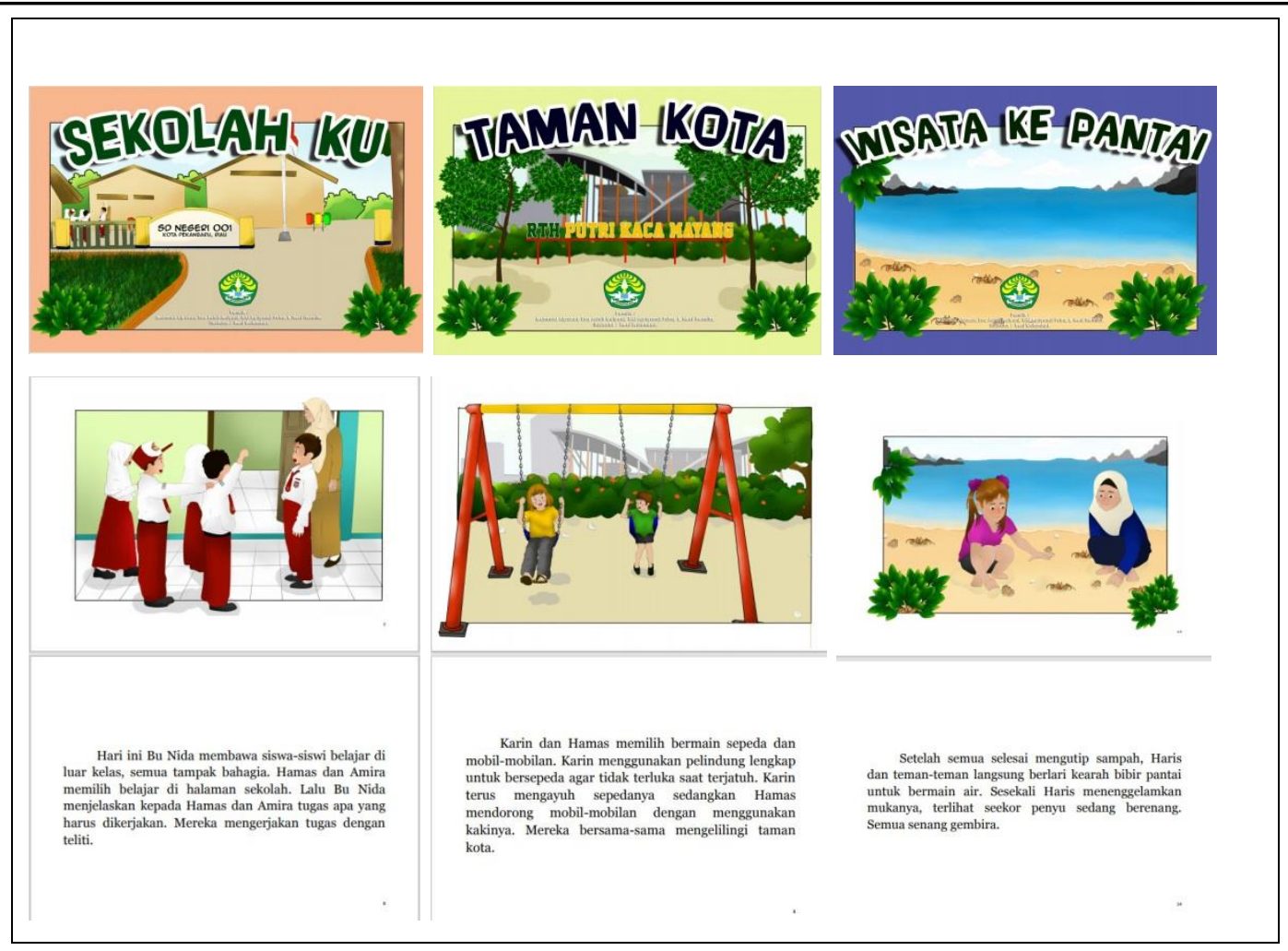

Gambar 1. Cover dan Isi Big Book

Tabel 1. Persentase Kriteria Validitas Big Book Taman Kota

\begin{tabular}{|c|l|c|l|}
\hline NO & \multicolumn{1}{|c|}{ ASPEK YANG DINILAl } & PERSENTASE & KATEGORI \\
\hline 1 & Indikator Materi & 92,19 & Sangat Layak \\
\hline 2 & Keakuratan materi & 80,63 & Layak \\
\hline 3 & Pendukung Materi & 86,72 & Sangat Layak \\
\hline 4 & Kemuktahiran Materi & 84,38 & Sangat Layak \\
\hline 5 & Lugas & 79,17 & Layak \\
\hline 6 & Komunikatif & 81,25 & Layak \\
\hline 7 & Dialoge dan interaktif & 90,63 & Sangat Layak \\
\hline 8 & $\begin{array}{l}\text { Kesesuaian dengan tingkat } \\
\text { perkembangan peserta didik }\end{array}$ & 84,38 & Sangat Layak \\
\hline 9 & $\begin{array}{l}\text { Keruntutan dan keterpaduan } \\
\text { alur piker }\end{array}$ & 84,38 & Sangat Layak \\
\hline 10 & $\begin{array}{l}\text { Penggunaan istilah, simbol, } \\
\text { atau ikon } \\
\text { Rata-rata }\end{array}$ & 83.87 & Sangat Layak \\
\hline
\end{tabular}

Berdasarkan data tabel 1 dapat dilihat judul big book taman kota bahwa kategori sangat layak pada aspek indicator materi, pendukung materi, kemuktahiran materi, dialog dan interaktif, Kesesuaian dengan tingkat perkembangan peserta didik, Keruntutan dan keterpaduan alur pikir dan 
TUNJUK AJAR: JURNAL PENELITIAN ILMU PENDIDIKAN

Volume 4, Nomor 1, February 2021

P-ISSN: 2615-062X

E-ISSN: 2622-3554

http://dx.doi.org/10.31258/ita.v4i1.86-95

Penggunaan istilah, simbol, atau ikon. Aspek kategori layak pada keakuratan materi, lugas dan komunikatif. Hasil rata-rata persentase 83.37 dengan kategori sangat layak.

Big book judul sekolahku memiliki persentase kriteria vailiditas dapat dilihat pada tabel berikut.

Tabel 2. Persentase Kriteria Validitas Big Book Sekolah Ku

\begin{tabular}{|c|l|c|l|}
\hline NO & \multicolumn{1}{|c|}{ ASPEK YANG DINILAI } & PERSENTASE & KATEGORI \\
\hline 1 & Indikator Materi & 85,94 & Sangat Layak \\
\hline 2 & Keakuratan materi & 80,63 & Layak \\
\hline 3 & Pendukung Materi & 82,03 & Sangat Layak \\
\hline 4 & Kemuktahiran Materi & 79,69 & Layak \\
\hline 5 & Lugas & 78,17 & Layak \\
\hline 7 & Komunikatif & 75 & Layak \\
\hline 8 & $\begin{array}{l}\text { Kesesuaian dengan tingkat } \\
\text { perkembangan peserta didik }\end{array}$ & 90,63 & Sangat Layak \\
\hline 9 & $\begin{array}{l}\text { Keruntutan dan keterpaduan } \\
\text { alur piker }\end{array}$ & 78,13 & Layak \\
\hline 10 & $\begin{array}{l}\text { Penggunaan istilah, simbol, } \\
\text { atau ikon }\end{array}$ & 78,13 & Layak \\
\hline & Rata-rata & 80,75 & Layak \\
\hline
\end{tabular}

Berdasarkan tabel 2 pada big book sekolahku memiliki aspek kategori sangat layak pada aspek Materi, Pendukung Materi dan Kesesuaian dengan tingkat perkembangan peserta didik. Sedangkan aspek layak pada aspek Keakuratan materi, Kemuktahiran Materi, Lugas, Komunikatif, Dialoge dan interaktif, Keruntutan dan keterpaduan alur pikir dan Penggunaan istilah, simbol, atau ikon. Rata - rata persentase pada aspek yang dinilai dengan kategor layak dengan persentase 80,75 .

Big book judul wisata kepantai memiliki persentase kriteria vailiditas dapat dilihat pada tabel 3. 
TUNJUK AJAR: JURNAL PENELITIAN ILMU PENDIDIKAN

Volume 4, Nomor 1, February 2021

P-ISSN: 2615-062X

E-ISSN: 2622-3554

http://dx.doi.org/10.31258/ita.v4i1.86-95

Tabel 3. Persentase Kriteria Validitas Big Book Wisata Kepantai

\begin{tabular}{|c|l|c|l|}
\hline NO & \multicolumn{1}{|c|}{ ASPEK YANG DINILAI } & PERSENTASE & \multicolumn{1}{|c|}{ KATEGORI } \\
\hline 1 & Indikator Materi & 85,94 & Sangat Layak \\
\hline 2 & Keakuratan materi & 80,63 & Layak \\
\hline 3 & Pendukung Materi & 82,03 & Sangat Layak \\
\hline 4 & Kemuktahiran Materi & 79,69 & Layak \\
\hline 5 & Lugas & 75 & Layak \\
\hline 7 & Komunikatif & 79,17 & Layak \\
\hline 8 & $\begin{array}{l}\text { Kesesuaian dengan tingkat } \\
\text { perkembangan peserta didik }\end{array}$ & 90,63 & Sangat Layak \\
\hline 9 & $\begin{array}{l}\text { Keruntutan dan keterpaduan } \\
\text { alur pikir }\end{array}$ & 78,13 & Layak \\
\hline 10 & $\begin{array}{l}\text { Penggunaan istilah, simbol, } \\
\text { atau ikon }\end{array}$ & 78,13 & Layak \\
\hline & Rata-rata & 80,64 & Layak \\
\hline
\end{tabular}

Berdasarkan tabel 3 pada big book wisata kepantai memiliki aspek kategori sangat layak pada aspek Materi, Pendukung Materi dan Kesesuaian dengan tingkat perkembangan peserta didik. Sedangkan aspek layak pada aspek Keakuratan materi, Kemuktahiran Materi, Lugas, Komunikatif, Dialoge dan interaktif, Keruntutan dan keterpaduan alur pikir dan Penggunaan istilah, simbol, atau ikon. Rata - rata persentase pada aspek yang dinilai dengan kategor layak dengan persentase 80,64.

Hasil penelitian menunjukkan bahwa validasi big book yang dibuat sudah bisa digunakan dalam proses pembelajaran, walaupun masih ada beberapa catatan dari validator. Hasil yang diperoleh tertera pada table 4.

Dari tabel 4 terlihat bahwa hasil yang diberikan dari validator menyatakan bahwa big book dengan judul taman kota dari segi kelayakan isi dan penilaian bahasa sudah sangat layak. Big book dengan judul sekolahku dan wisata kepantai untuk kelayakan isi big book dengan kriteria sangat layak, sedangkan penilaian bahasa dengan kriteria layak. 
TUNJUK AJAR: JURNAL PENELITIAN ILMU PENDIDIKAN

Volume 4, Nomor 1, February 2021

P-ISSN: 2615-062X

E-ISSN: 2622-3554

http://dx.doi.org/10.31258/ita.v4i1.86-95

Tabel 4. Hasil Validasi Big Book

\begin{tabular}{|l|l|l|l|l|}
\hline No & \multicolumn{1}{|l|}{$\begin{array}{c}\text { Judul } \\
\text { Buku }\end{array}$} & $\begin{array}{l}\text { Kelayakan } \\
\text { Isi Big } \\
\text { Book }\end{array}$ & $\begin{array}{c}\text { Penilaian } \\
\text { Bahasa Big } \\
\text { Book }\end{array}$ & \multicolumn{1}{c|}{ Keterangan } \\
\hline 1 & $\begin{array}{l}\text { Taman } \\
\text { Kota }\end{array}$ & $\begin{array}{l}86 \% \\
\text { Sangat } \\
\text { layak }\end{array}$ & $\begin{array}{l}82.5 \% \\
\text { Sangat } \\
\text { layak }\end{array}$ & $\begin{array}{l}\text { Layak digunakan dengan } \\
\text { catatan harus diperbaiki } \\
\text { sebelum digunakan }\end{array}$ \\
\hline 2 & Sekolahku & $\begin{array}{l}82.1 \% \\
\text { Sangat } \\
\text { layak }\end{array}$ & $\begin{array}{l}79,9 \% \\
\text { layak }\end{array}$ & $\begin{array}{l}\text { Layak digunakan dengan } \\
\text { catatan harus diperbaiki } \\
\text { sebelum digunakan }\end{array}$ \\
\hline 3 & $\begin{array}{l}\text { Wisata } \\
\text { Kepantai }\end{array}$ & $\begin{array}{l}82.1 \% \\
\text { Sangat } \\
\text { layak }\end{array}$ & $\begin{array}{l}79,7 \% \\
\text { layak }\end{array}$ & $\begin{array}{l}\text { Layak digunakan dengan } \\
\text { catatan harus diperbaiki } \\
\text { sebelum digunakan }\end{array}$ \\
\hline
\end{tabular}

\section{SIMPULAN}

Pengembangan media pembelajaran big book dilaksanakan melalui tahapan yaitu: analisis kebutuhan, mengembangkan produk awal, validasi para ahli dan revisi produk. Pada proses penilaian pada ketiga judul big book yang dilakukan oleh para ahli, kelayakan isi materi diperoleh persentase nilai untuk judul Sekolahku 82,1\% dengan kategori sangat layak; Wisata ke Pantai 82,1\%; dan Taman Kota 86\%. Sedangkan untuk penilaian bahasa big book diperoleh persentase nilai untuk Sekolahku 79,9\%; Wisata ke Pantai 79,7\%; dan Taman Kota $82,5 \%$. Dengan kesimpulan media pembelajaran big book layak untuk diujicobakan dengan revisi sesuai saran.

\section{DAFTAR PUSTAKA}

Febriyanti, D., \& Putra, Z. H. (2020). Development of 3-Dimensional Snake and Ladder Game: Implementation with Second Grade Students of SDN 37 Pekanbaru. Jurnal PAJAR (Pendidikan dan Pengajaran), 4(6), 1140 - 1151.

Fink, D. L. (2003). A Self-Directed Guide to Designing Courses for Significant Learning. Oklahoma: University of Oklahoma.

Hall, S. C., \& O"connor, B. (2006). Using Big Books: A Standards-Based Instructional Approach for Foreign Language Teacher Candidates in a PreK12 Program. Foreign Language Analysis, 39(3). 
TUNJUK AJAR: JURNAL PENELITIAN ILMU PENDIDIKAN

Volume 4, Nomor 1, February 2021

P-ISSN: 2615-062X

E-ISSN: 2622-3554

http://dx.doi.org/10.31258/ita.v4i1.86-95

Lynch, P. (2008). Using Big Books and Predictable Books. Canada: Scholastic Canada Ltd.

Mcknight, K. S. (2010). The Teacher's Big Book of Graphic Organizers. San Francisco: Jossey-Bass.

Mortimer. A., \& Charles van. D. (2011). Meraih Kecerdasan: Bagaimana Seharusnya Anda Meraih Manfaat Hebat dari Bacaan?, Bandung: Nuansa.

Mulyatiningsih, M. (2011). Metode Penelitian Terapan Bidang pendidikan.

Alfabeta. Bandung.

Nambiar, M. (1993). Early Reading Instruction Big Books in the ESL Classroom. Jurnal The English Teacher (Vol XXII).

Putri, F. Z., Putra, Z. H., \& Munjiatun, M. (2021). Pengembangan Media Kartu Domino Materi Pecahan untuk Belajar Mandiri Siswa Kelas IV SDN 147 Pekanbaru di Masa New Normal, Jurnal IImiah Aquinas, 4(1), 113 - 126.

Rusminiati. (2018). Peningkatan Keterampilan Membaca Permulaan Menggunakan Media Kubus Suku Kata Siswa Sekolah Dasar. Jurnal $\begin{array}{lllll}\text { Pendidikan dan Pembelajaran Khatulistiwa. Vol } 7 . & \text { No.3. }\end{array}$ e-ISSN: 2715-2723. https: // jurnal.untan.ac.id /index. Php /jpdpb /article / view /24512

Satria, T. G., \& Hajani, T. J. (2020). Development of Thematic Skill Learning Based on the 21st Century Skill Model for Fourth Graders. Journal of Teaching and Learning in Elementary Education, 3(1), 47 - 57.

Sugiyono, S. (2013). Cara Mudah Menyusun Skripsi, Tesis, dan Disertasi. Bandung: Alfabeta.

Suhandi, A., \& Pamela, I. S. (2019). Analisis Kebutuhan Pengembangan Model Pembelajaran BBM3 untuk Meningkatkan Metakognisi Mahasiswa. Tunjuk Ajar: Jurnal Penelitian IImu Pendidikan, 2(2), 102-110.

Tanoto Foundation (2019). Modul II Praktik yang Baik dalam Pembelajaran di SD dan MI Literasi Kelas Awal. Modul Lokakaarya. Jakarta: Tanoto.

Tarigan, H.G. (1990). Membaca Sebagai Suatu Keterampilan Berbahasa.

Bandung: Penerbit Angkasa.

Usaid Prioritas. (2014). Pembelajaran Literasi Kelas Awal di LPTK: Buku Sumber Untuk Dosen LPTK. Jakarta: Usaid. 
TUNJUK AJAR: JURNAL PENELITIAN ILMU PENDIDIKAN

Volume 4, Nomor 1, February 2021

P-ISSN: 2615-062X

E-ISSN: 2622-3554

http://dx.doi.org/10.31258/ita.v4i1.86-95

Usaid Prioritas. (2015). Materi untuk Sekolah Praktik yang Baik Sekolah Dasar/Madrasah Ibtidaiyah (SD/MI): Modul Lokakarya. Jakarta: Usaid.

Widoretno, P. (2014). Pengembangan LKS Dengan Pembelajaran Berbasis Masalah Pada Materi Diagram Gaya Normal, Gaya Lintang, dan Momendi Kelas X TGB 1 SMK Negeri 1 Sidoarjo. Jurnal Kajian Pendidikan Teknik Bangunan 3 (1) (Online).http : / / journal . walisongo . ac . I / index . php / phen / issue/view/31. (diakses 29 Oktober 2020). 